*Professor da Faculdade de Direito da Universidade Presbiteriana Mackenzie (UPM). Pós-Doutorando pelo Instituto de Relações Internacionais da Universidade de São Paulo (IRI-USP). Doutor em Direito pela Universidade de São Paulo (USP) com período sanduíche na University of Califórnia, Los Angeles. Mestre em Direito e Desenvolvimento pela Fundação Getúlio Vargas (FGV). Graduado em Filosofia pela Universidade de São Paulo (USP). Bacharel em Direito pela Pontifícia Universidade Católica de São Paulo (PUCSP). Email: marcoloschiavo@gmail.com

\section{Direitos Econômicos, Sociedade E O Supremo Tribunal Federal: Observando A Atuação Da Corte no Controle Abstrato}

\author{
Economic Rights, Society And The Brazilian Superme \\ Court: Observing The Court's Abstract Judicial \\ REVIEW PERformance
}

\section{Marco Antonio Loschiavo Leme de Barros*}

Como citar: BARROS, Marco Antonio Loschiavo Leme de. Direitos econômicos, sociedade e o supremo tribunal federal: observando a atuação da corte no controle abstrato. Scientia Iuris, Londrina, v. 24, n. 1, p. 99-123, mar. 2020. DOI $10.5433 / 21788189.2020 \mathrm{v} 24 \mathrm{n} 1 \mathrm{p} 99$. ISSN 2178-8189.

Resumo: Este texto examina a atuação do Supremo Tribunal Federal no controle abstrato de normas no ordenamento em relação à proteção dos direitos econômicos previstos na Constituição da República Federativa do Brasil de 1988. Por meio da apresentação de uma amostra de julgamentos da corte sobre a matéria, observa-se a operação decisória do tribunal, bem como são delimitados alguns aportes sociológicos que servem como ponto de partida para a reflexão sobre a relação entre o tribunal e a sociedade. Questiona-se: (i) O que autoriza juízes (não eleitos) a implementar políticas econômicas que são necessariamente premissas para um efetivo gozo dos direitos fundamentais? (ii) Afinal, na prática, tribunais são institucionalmente capazes de lidar com as complexas questões técnicas e políticas que permeiam este tema? Na primeira indagação, discute-se a legitimidade dos juízes; na segunda, são trazidas a lume questões internas sobre a estrutura e a operação dos tribunais. No final, considerando o caso brasileiro, o texto indica as dificuldades de o Supremo Tribunal Federal gerir as incertezas jurídicas da economia, que, por vezes, acarreta maior turbulência social e, simultaneamente, revela a necessidade de uma maior abertura para a inovação e a cooperação entre as organizações sociais do direito.

Palavras-chave: Direitos econômicos. Supremo Tribunal Federal. Sociologia do Direito. Decisão.

Abstract: This paper examines the role of Brazil's Supreme Court from an abstract judicial review because it helps to protect economic rights guaranteed by the Constitution of the Federative Republic of Brazil of 1988. From an empirical examination of court judgments regarding economic rights, it is possible 
to understand the decision-making-process, as well as some sociological contributions that serve as a starting point for an important reflection between court and society. This study address two main questions: (i) What authorizes (unelected) Brazilian judges to implement economic policies that are necessary for the effective enjoyment of fundamental rights? (ii) Moreover, in practice, are courts institutionally capable of dealing with the complex technical and political issues that permeate this theme? The first question deals with the issue of the legitimacy of judges; and the second question highlights internal questions about the structure and operation of Brazilian courts. Finally, considering Brazil as a nation, this paper indicates the difficulties of the Brazilian Supreme Court in managing legal uncertainties that may impact the economy, sometimes causing even greater social turmoil and, at the same time, reveals the need for openness of the legal system in regards to innovation and cooperation between the many social institutions of law.

Keywords: Economic rights. Supreme Federal Court. Sociology of Law. Decision. 


\section{INTRODUÇÃO}

O direito econômico é um ramo jurídico de difícil definição em virtude da variedade e abrangência de seu conteúdo, cujo desenvolvimento foi constatado no início do século XX. Ao longo da história é possível notar diferentes experiências qualificadas como "econômicas" pelo sistema jurídico, tais como: direito do desenvolvimento; direito do planejamento econômico; direito da concorrência ou, ainda, direito da regulação dos mercados. ${ }^{1}$

Para algumas perspectivas mais radicais - como a posição do jurista italiano Francesco Carnelutti - a vinculação entre direito e economia é, em verdade, uma constatação de origem já que a guerra, a propriedade e o contrato podem ser reputados como fenômenos econômicos antes de serem jurídicos. A tarefa, então, de definir um conteúdo para o direito econômico perde propósito já que qualquer matéria jurídica possui sempre um fundo econômico na sociedade.

A despeito da dificuldade de encontrar uma definição última sobre direito econômico prevalece um ponto em comum em relação a todas as experiências mencionadas: o direito econômico viabiliza o tratamento jurídico de uma política econômica e, com efeito, dos agentes (públicos e privados) que dela participam. ${ }^{2}$ Este texto argumenta que o direito econômico é uma área transformadora do direito, pois, exige, a todo o momento, das organizações jurídicas uma revisão sobre como a adjudicação deva ocorrer para zelar uma política econômica.

Assim, para decidir sobre demandas envolvendo direitos econômicos, a autoridade necessita saber primeiro como operar com o fato econômico, seja via exame da eficiência (eg., análise econômica do direito), mas também por meio de outras metodologias jurídicas e extrajurídicas. O desafio é entender como o direito traduz o fato econômico, eventualmente produzindo uma nova comunicação e delimitando uma nova fronteira entre os sistemas jurídico, político e econômico - em verdade, esta definição dos limites requer a observação das operações das organizações jurídicas. ${ }^{3}$

Desde 1934, durante o governo de Getúlio Vargas, observou-se a constitucionalização dos direitos econômicos no país. Isto significa que no Brasil, o direito é tanto forma prioritária e superior de organizar a ordem econômica (art. 170, CF/88), mas também meio de realizá-la por meio de políticas econômicas constitucionais - basta considerar as políticas de redução das desigualdades regionais (art. $3^{\circ}$, II e III da CF/88), da política urbana (art. 182, da CF/88), da política agrícola e fundiária (art. 184 e seguintes, da CF/88) ou da política de incentivo a micro

1 As normas de direito econômico disciplinam desde ações para o desenvolvimento, como a elaboração de planos econômicos, dirigindo-se à toda a coletividade, mas também se reservam a proteger direitos subjetivos individuais, por exemplo, ao possibilitar as operações de fusões e aquisições nos mercados ou ao reprimir o abuso de poder econômico de um dado agente econômico.

2 Vale resgatar Carnelutti (2001, p. 37) ao afirmar que "o contato é um instrumento jurídico sem o qual não poderiam atuar as duas formas fundamentais da colaboração econômica: o intercambio e a associação. Os dois contratos típicos, sob este aspecto, são a venda e a sociedade, mas em torno deles veio florescendo e constantemente germina novamente uma flora contratual maravilhosamente rica". A "flora contratual" mencionada pelo jurista italiano pode representar justamente a questão do tratamento jurídico da economia (ie., área da interpretação e argumentação jurídica), ponto tematizado neste texto.

3 Fábio Konder Comparato (2012, p. 472), observando a peculiaridade em relação ao método de aproximação entre direito e economia retrata com precisão o chamado "indispensável direito econômico", pois "o surgimento do direito econômico representa um estímulo constante ao aperfeiçoamento das instituições jurídicas em função de seus objetivos concretos. A compreensão do direito como técnica incita à crítica e à renovação incessante do direito positivo". 
e pequenas empresas (LC 123/2006). Estas políticas inseridas no texto constitucional, definemse por normas constitucionais programáticas, que estabelecem objetivos e metas que devem ser concretizadas pela Administração Pública.

Todavia, nas últimas décadas, o que se observou foram uma série de dificuldades na concretização dessas normas, revelando uma tensão entre os sistemas sociais e mediadas por diferentes operações organizacionais: tribunais; bancos; Estados e empresas estão imbricados a partir de diferentes relações jurídicas, com o intento de assegurar a ordem econômica.

Os tribunais, por exemplo, se transformaram num importante centro decisório destas políticas no país. Desde a superação da cultura dos juízes "boca da lei”, com o progressivo aumento de legislações que autorizam expressamente uma integração via argumentação e interpretação judicial na aplicação da lei, consolidou-se a discussão sobre ativismo judicial vis-àvis judicialização da política, ${ }^{4}$ o que também releva uma discussão de fundo sobre os limites e o papel dos juízes na sociedade.

Qual é o papel dos tribunais em relação à efetivação dos direitos econômicos? De um lado, o ativismo enfatiza o exame dos comportamentos dos juízes. Argumenta-se que "é uma estratégia mais expansiva e proativa de interpretação do direito, usada pelos juízes para maximizar o sentido e o alcance das normas constitucionais." (FARIA, 2017). Ativismo é uma visão exógena do papel dos juízes, que combina com o diagnóstico sobre a omissão e a ineficiência da atuação dos demais poderes do Estado, e que, em tese, justificaria a conduta proativa dos juízes em protegerem os direitos fundamentais ao julgarem os casos. Do ponto de vista do direito econômico, tal posição impõe a autoridade um ônus argumentativo maior já que implica em construção e aplicação de métricas que viabilizem o exame das consequências econômicas da decisão.

Do outro lado, a judicialização da política enfatiza a constante ampliação da forma do direito na sociedade, que, por sua vez, significa a juridificação de todo e qualquer problema social. Destaca-se que "é um fenômeno resultante da crescente complexidade socioeconômica do país, o que obrigou a Constituição a ter de tratar de uma ampla gama de matérias que antes eram deixadas para a legislação ordinária" (FARIA, 2017).

Judicialização é uma visão endógena do papel dos juízes, que se ajusta com o diagnóstico da transformação da legislação e da interpretação jurídica no interior do direito após a promulgação da CF/88. Cada vez mais se observa a positivação de textos legais abertos e flexíveis no país, que se valem de diretrizes e princípios jurídicos para orientar a solução dos casos - como é o caso do princípio da liberdade econômica, base central que protege a ordem econômica brasileira via a livre iniciativa e a liberdade de trabalho. ${ }^{5}$

4 Para uma apresentação completa desta transformação veja Ferraz Junior (2014).

5 É possível interpretar esse movimento à luz do fenômeno do hiperpluralismo indicado por Karl-Heinz Ladeur (2016) ao mencionar o incessante alargamento de funções estatais que exige novas intervenções, bem como criam novos problemas de regulação. Diz o jurista alemão: “[...] em todos os países industrializados do ocidente, o pluralismo clássico do Estado Social, que se baseava nos grandes grupos sociais representativos, encontra-se em ruínas. Seu lugar é tomado por uma multiplicidade de pequenos grupos operantes e bem organizados de novos processos da fragmentação de interesses, aos quais também se acrescentam, crescentemente, o próprio interesse de funcionários públicos e de seus clientes na conservação de "deveres de proteção" exigidos por programas de assistência. Com essa constatação, não se trata de depreciar a legitimação política do legislador. Trata-se, entretanto, de conferir mais contornos às constituições intrínsecas da auto-organização social da econômica, dos meios de comunicação etc., que 
Tais perspectivas podem ser consideradas como faces da mesma moeda, pois a discussão de fundo tanto no ativismo como na judicialização é a ampliação do poder judicial na sociedade 6 e, no caso desse texto, esta discussão está relacionada com a questão sobre como o direito traduz o fato econômico. O problema é entender, então, como e o que esta ampliação representa à luz dos casos concretos.

Para alguns autores (GARGARELLA; DOMINGO; ROUX, 2006), é possível aceitar esta ampliação na medida em que representaria o aumento do acesso à justiça. $\mathrm{O}$ ativismo poderia supor, por exemplo, uma maior aproximação dos juízes com a sociedade, pois ao observar que, agora, qualquer cidadão pode recorrer ao tribunal para proteger os seus direitos fundamentais, aí incluído o controle de políticas públicas que foram constitucionalizadas. A dificuldade estaria, então, em formular desenhos institucionais ótimos que assegurem o acesso prioritário de demandas mais graves e concretize a igualdade material de maneira eficiente na sociedade.

Outros autores (TUSHNET, 1999; WALDRON, 2014) seguem uma linha mais crítica em relação à ausência da legitimidade democrática para justificar este aumento dos poderes dos juízes. Subjacente à posição está a defesa da regra da maioria dos mandatários vis-à-vis as decisões judiciais. Discute-se, portanto, o papel contramajoritário dos juízes e as limitações que este papel impõe na articulação com os outros poderes do Estado, inclusive alertando para o risco de um governo dos juízes.

Este texto adota um outro caminho. Acredita-se que a sociologia jurídica pode revelar novas tensões não debatidas por entusiastas do ativismo ou da judicialização em relação à efetivação dos direitos econômicos. Sustenta-se que, na visão sociológica, sobretudo de raiz sistêmica, o interesse recaí na observação da fixação dos limites do sistema do direito em relação ao ambiente social, bem como da constatação das operações organizacionais que transitam entre diferentes subsistemas sociais e produzem uma comunicação diferenciada em relação ao direito econômico. ${ }^{7}$

Por sinal, estas operações organizacionais confirmam a aquisição e transformação do conhecimento na sociedade, pois "direitos fundamentais como direito subjetivo tem efeitos transubjetivos bastante importantes que residem na autonomia da auto-organização dos âmbitos sociais funcionais (economia, mídia, artes etc.)" (LADEUR, 2016, p. 199). Isto exige entender que a prestação desses direitos não depende apenas na centralização da atuação do Estado, mas, em verdade, na observação da auto-organização da sociedade em diferentes âmbitos funcionais via o desenvolvimento de um direito cooperativo e inovador. ${ }^{8}$

Afirma-se que o tema do ativismo ou da judicialização é, na verdade, um debate sobre os

são garantidas por meio de direitos fundamentais." (LADEUR, 2016, p. 139).

6 Veja a discussão apresentada por Nobre e Rodriguez (2011).

7 Em Direito da Sociedade Niklas Luhmann (2016, p. 274-281) - importante representante da sociológica sistêmica - já indicava isto quando sustentava a transformação da organização do tribunal na sociedade, que cada vez mais passou a assumir a centralidade do sistema para se isolar cognitivamente, mas também para assegurar o fechamento operativo do sistema. Qualquer tipo de demanda ensejaria uma decisão judicial, garantida pela vedação do non liquet.

8 Para algumas leituras é o caso de resgatar e complementar o modelo clássico liberal de direito, diz Ladeur (2016, p. 197): "Quando o Estado age de forma não paternalista, ele almeja distanciar-se da realidade produzida pela sociedade. Portanto, uma concepção liberal de direitos fundamentais, consequentemente, deveria perguntar-se se e até que ponto a sociedade (pós) moderna realmente se transformou e como o Estado e a Ordem Jurídica reagiriam a tal transformação, porém sem pressupor as tarefas de distribuição e alocação de forma incontestada e irrefletida." 
limites estabelecidos pelo sistema jurídico, que são revistos a todo instante quando o juiz decide as controvérsias. O interesse, portanto, reside na observação sociológica da argumentação jurídica, que deve ser parte integrante de uma teoria social que observa, simultaneamente, a autodescrição do direito e a da sociedade.

Este texto não busca defender modelos ou programas decisórios, mas busca compreender como estes limites são delineados pelos juízes no âmbito decisório de demandas envolvendo direitos econômicos no Brasil. Como será visto, ponto de destaque é entender o desenvolvimento de uma argumentação consequencialista nos tribunais, orientada para verificar os efeitos em disputa. Para tanto, este texto se vale de uma pesquisa jurisprudencial acerca da atuação do Supremo Tribunal Federal (STF), no controle abstrato de normas no ordenamento em relação à proteção dos direitos econômicos previstos na Constituição da República Federativa do Brasil (CF/88), nos últimos trinta anos (1988-2018) de atuação desta corte.

Por meio da apresentação de uma amostra de julgamentos sobre a matéria, discute-se o comportamento decisório do tribunal, bem como são delimitados alguns aportes sociológicos que servem como ponto de partida para refletir sobre a relação entre o tribunal e a sociedade no país. Questiona-se: (i) O que autoriza juízes (não eleitos) a implementar políticas econômicas que são necessariamente premissas para um efetivo gozo dos direitos à saúde, educação, habitação entre outros? (ii) Afinal, na prática, tribunais são institucionalmente capazes de lidar com as complexas questões técnicas e políticas que permeiam este tema?

$\mathrm{Na}$ primeira indagação, discute-se a legitimidade dos juízes; na segunda, são trazidas a lume questões internas sobre a estrutura e a operação dos tribunais. No final, considerando o caso brasileiro, o texto indica as dificuldades de o STF gerir as incertezas jurídicas da economia, que, por vezes, acarreta maior turbulência social e, simultaneamente, revela a necessidade de uma maior abertura para a inovação e a cooperação entre as organizações sociais do direito.

\section{NOTAS METODOLÓGICAS}

Para discutir o tema da fixação dos limites do direito pelos juízes, o texto se vale de uma pesquisa jurisprudencial. A amostra é composta por julgados extraídos do STF; a opção por este tribunal justifica-se por sua posição como órgão de sobreposição responsável por assentar o entendimento e a interpretação do direito brasileiro, proferindo a última decisão nas matérias de sua competência, além da própria interface de uma corte constitucional em razão do acoplamento estrutural entre direito e política numa leitura sistêmica.

Diante deste recorte institucional, optou-se por trabalhar com a adjudicação de julgados referentes à aplicação de direitos econômicos assegurados constitucionalmente. Por direitos econômicos entendem-se temas relativos às normas de regulamentação da economia afetas às políticas cambial, monetária, salarial e de preços; e direitos sociais são casos conexos aos direitos da ordem social. Estes temas foram selecionados em razão da grande quantidade de normas programáticas que fixam objetivos e regras a estes direitos. 
Vale destacar que no âmbito do direito econômico o STF se tornou verdadeiro protagonista em razão da proteção do Título VII “Da Ordem Econômica e Financeira”, da CF/88. Recentes julgados da corte viabilizam o exercício da atividade econômica em face de novas relações de produção, consagrada no país por meio da livre iniciativa e da liberdade profissional. Importante exemplo foi a decisão que protegeu a operação de serviços remunerados de transporte de passageiros por aplicativos em face da coerção arbitrária por parte do Estado (BRASIL, 2019).

Procedeu-se, ainda, a um recorte processual, selecionando-se apenas casos de controle concentrado de constitucionalidade (ADI, ADI por omissão, ADC e ADPF) e com decisão já transitada em julgado, incluindo julgamentos monocráticos. Esta limitação é necessária em decorrência da quantidade de casos disponíveis, embora se admita a possibilidade de recortes por outros meios, sobretudo o recurso extraordinário. ${ }^{9} \mathrm{O}$ respeito pelo trânsito em julgado é importante para que sejam analisados os argumentos vencedores e a eventual estabilidade das decisões da Corte diante de situações anteriores similares.

Cumpre lembrar que não se pretende, aqui, esgotar e codificar todos os casos possíveis nem apresentar uma palavra final sobre a adjudicação de direitos econômicos pelo STF. O interesse reside em verificar como os juízes fixam os limites do direito, por isso acredita-se que a observação sobre como os argumentos consequencialistas são mobilizados em algumas situações seja suficiente para indicar este propósito.

Em muitos casos de adjudicação de direitos econômicos, o juiz, ao decidir, acaba considerando em alguma medida as consequências de sua decisão de diferentes maneiras, seja para enfrentá-las ou não na solução da demanda. Admite-se, neste texto, que uma das formas de raciocínio jurídico é a que se desenvolve por meio dos argumentos de consequência ou do argumento consequencialista, aquele operado pelo tribunal a partir das consequências da decisão, independentemente do que tenha sido admitido e avaliado pela decisão.

Ao observar e analisar a crescente utilização de argumentos consequencialistas em juízo, é possível precisar o fenômeno da expansão da atuação dos juízes e tribunais para além do direito e compreender os efeitos da expansão da sua operação em outros sistemas (i.e., econômico e político). Destarte, a amostra abrange jurisprudência do STF sobre controle concentrado de constitucionalidade relativo a direitos econômicos e sociais com repercussões econômicas com decisão transitada em julgado, incluindo julgamentos monocráticos, no período de 1988 a 2016. A partir desta delimitação, a busca realizou-se pela inclusão de palavras-chave no link "Pesquisa de Jurisprudência" do site do STF (http://www.stf.jus.br/portal/jurisprudencia/pesquisarJurisprudencia.asp), especificamente os termos "política cambial", "monetária", "salarial” e de "preços", “ordem social”, "saúde", "educação", "cultura" e "seguridade social”. Após a filtragem, a amostra foi comparada e ajustada com duas contraprovas. ${ }^{10}$

9 Sublinhe-se, inclusive, que muitos casos de controle de constitucionalidade acontecem de forma concreta e difusa pelos recursos extraordinários, o que não se discute no texto. 10

As contraprovas utilizadas foram o banco de dados do STF na área "Estatística do STF/Controle 
Os resultados de controle concentrado com decisão final totalizam 3.045 casos, dos quais 301 (aproximadamente 10\%) formam a população amostral da pesquisa:

Tabela 1 - Casos analisados

\begin{tabular}{|l|l|l|l|}
\hline \multicolumn{4}{|c|}{ Casos analisados por tipo de controle } \\
\hline 281 ADIs & 4 ADIs por omissão & 2 ADCs & 14 ADPFs \\
\hline
\end{tabular}

Fonte: Autor

A população amostral foi tabulada segundo os códigos construídos para extração do resultado, elaborados para responder às perguntas da pesquisa e atingir o objetivo deste texto. Os campos foram preenchidos com leitura do inteiro teor de todas as decisões finais (a última decisão de mérito), fossem elas acórdãos ou decisões monocráticas. Além dos dispositivos, foram considerados na leitura todos os votos disponibilizados por cada Ministro. Não se pode perder de vista que ações de controle de constitucionalidade comportam medidas cautelares, decisões finais (monocráticas ou colegiadas), embargos declaratórios e decisões em agravo regimental; por isso, houve o cuidado de observar se em tais atos existia algum argumento importante a ser analisado. ${ }^{11}$

Destarte, o texto apresenta o banco de dados e a análise quantitativa a fim de possibilitar uma observação crítica dos julgados. O banco de dados permitiu extrair padrões sobre como o STF atua em casos que exigem o exame de circunstâncias fáticas e de efeitos de programas governamentais, bem como compreender como a corte se comportou ao longo das últimas décadas. No final, o texto aponta, em termos sistêmicos, a própria autodescrição produzida pela corte, indicando os diferentes limites do sistema jurídico brasileiro traçados pelos próprios Ministros.

\section{ANÁLISE QUANTITATIVA DA AMOSTRA}

Os temas da amostra incluem preponderantemente casos de direito econômico, em relação aos casos de direito social com repercussão econômica.

\section{Figura 1 - Tema}

Fonte: Autor

A busca resultou em 252 casos de direito econômico vis-à-vis 49 de social com repercussão econômica. Numa subdivisão, as principais controvérsias no campo econômico versavam sobre regulação da atividade econômica, sistema de consórcios e sorteios e consumo (figura 2).

concentrado" (http://www.stf.jus.br/portal/cms/verTexto.asp?servico=estatistica\&pagina=adi) e o banco de dados da pesquisa de Oliveira (2016).

11 Deve ser lembrado que as ações de controle de constitucionalidade podem apresentar medidas cautelares, decisões finais (monocráticas ou colegiadas), embargos declaratórios e decisões em agravo regimental. Neste caso adotou-se o cuidado de observar se em tais atos existia algum argumento importante para ser analisado. 
Figura 2 - Assunto da controvérsia em direito econômico

Fonte: Autor

No que tange aos temas da ordem social comrepercussão econômica, destacam-se educação, previdência e contribuição social e saúde - tais temas discutiam a disponibilidade econômica da Administração Pública para o atendimento de políticas públicas diante da responsabilidade pela execução do Orçamento Público, que, por vezes, busca afastar a exigibilidade de uma prestação social invocando a denominada reserva do possível.

Figura 3 - Assunto da controvérsia em Direito Social

Fonte: Autor

É importante, também, saber os resultados e como foi tomada a decisão nestes casos. Confirmou-se uma hipótese demonstrada por outras análises de que predominam no STF atuações monocráticas, em detrimento da forma colegiada, provocando um esvaziamento do plenário em casos de controle concentrado de constitucionalidade. ${ }^{12}$

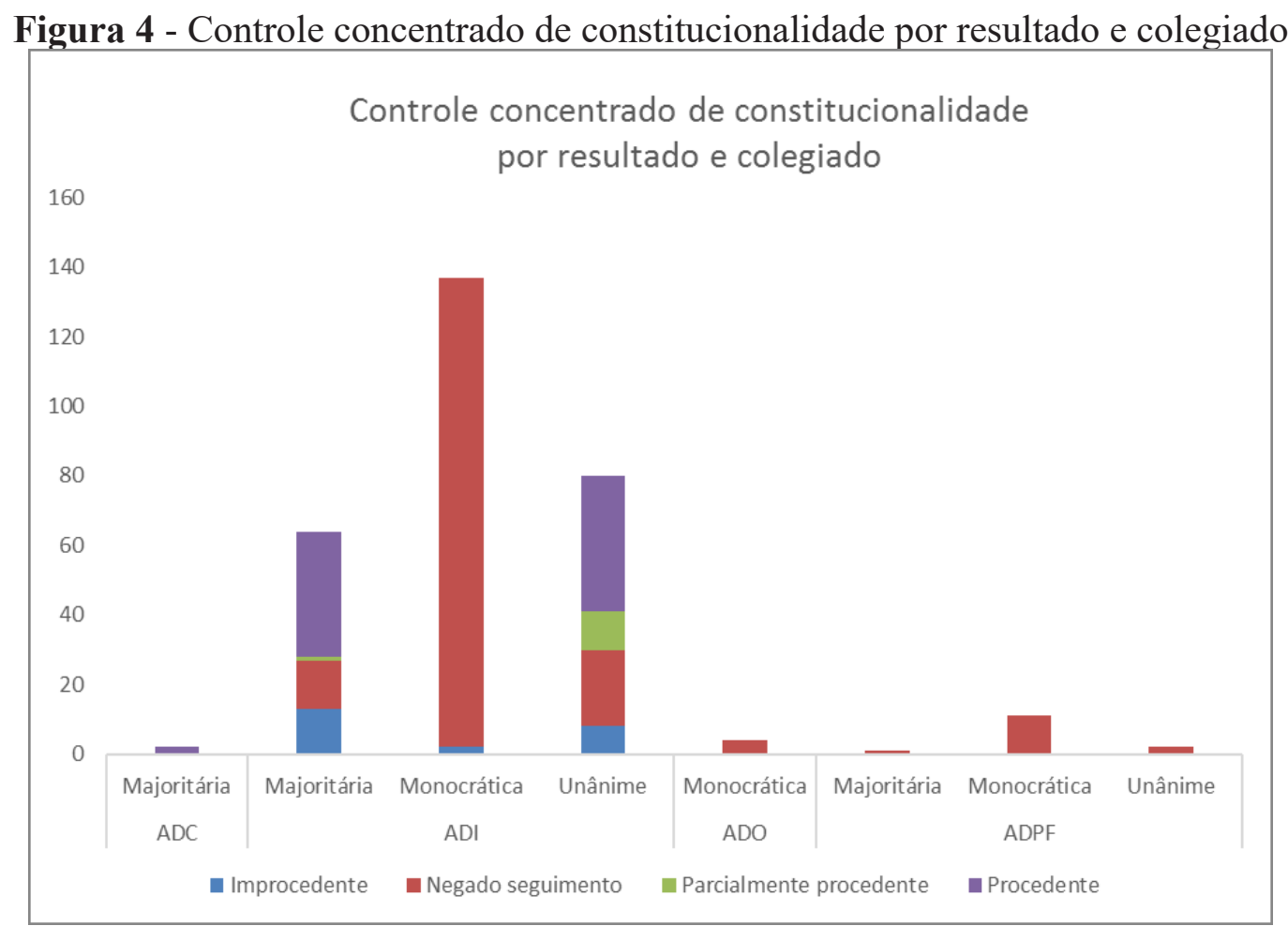

Fonte: Autor

Vislumbra-se, portanto, que à maioria dos casos analisados foi negado seguimento, de forma monocrática, sobretudo em ADIs e ADPFs. Na totalidade dos casos de procedência ou parcial procedência respeitou-se a colegialidade, principalmente nas ADIs.

12Cf., nesse sentido, Falcão, Cerdeira e Arguelhes (2011) e Falcão, Arguelhes e Recondo (2017). 
Figura 5 - Decisão final versus fundamentos da decisão

Fonte: Autor

Dentre os casos aos quais foi negado seguimento, 114 justificaram-se por perda do objeto da ação. Em relação aos casos procedentes e parcialmente procedentes, 61 casos alegavam desrespeito e invasão da competência privativa da União provocada pelo legislador estadual ou pelo governador. Cumpre observar que, de fato, poucas decisões de mérito fundamentaram-se predominantemente nos princípios que justificam a ordem econômica e social e, ainda que estes princípios fossem mencionados nos votos, não se encontravam reproduzidos nas ementas da decisão.

A série temporal de propositura de processos novos e o tempo de demora para a tomada de decisão também revela dados interessantes. Os anos em que se observa a maior ocorrência de propositura de ações de controle concentrado em direitos econômicos e sociais foram 1997 (presidência do Ministro Celso de Mello) e 2003 (presidência do Ministro Maurício Corrêa), sendo que a partir de 1998 a corte reduziu o tempo de demora para a tomada de decisão final para cinco anos ou menos, e em 2012 para dois anos ou menos (figura 6).

Figura 6 - Processos protocolados por ano versus média anual para tomada de decisão Fonte: Autor

A relação dos autores, por sua vez, é apresentada na figura 7.

Figura 7 - Autores dos processos

Fonte: Autor

Os órgãos da Associação/Confederação/Sindicato foram autores de 114 casos, seguidos por Governadores e Partidos Políticos. Esta prevalência pode ser explicada ao se considerar a legitimidade e o interesse especial da Associação/Confederação/Sindicato conforme os temas e assuntos mobilizados.

O achado é confirmado por pesquisas que apontam a frequente atuação estratégica de Partidos Políticos e de certos atores do Poder Executivo com o intuito de modificar decisões majoritárias nas quais foram derrotados por via legislativa ${ }^{13}$ e fica mais evidente com o dado de que a maioria das ações propostas por Governadores eram requeridas em face do Legislativo Estadual equivalente.

A fonte dos fundamentos e, sobretudo, a mobilização dos argumentos consequencialistas estão ilustradas na figura 8 .

13 Cf., neste sentido, Taylor (2008). 
Figura 8 - Fundamentos

Fonte: Autor

O gráfico acima ilustra as fontes utilizadas nos julgados para fundamentar as decisões. Para categoria, a resposta foi "sim" ou "não", de modo que, do total, 287 recorreram à legislação e 226, à jurisprudência. Para essas categorias, consideraram-se apenas as ocorrências originais no texto dos votos, e não aquelas contidas em citações de julgados anteriores ou do dispositivo.

Somente em poucos casos não houve referência à legislação - precipuamente, nas decisões monocráticas por perda de objeto, talvez pela exigência mais branda quanto aos fundamentos de uma decisão desta natureza. Observou-se, ainda, um cuidado da Corte em citar e respeitar decisões passadas, demonstrando, na grande maioria dos casos, que Ministros preocupavam-se com as consequências das decisões no ordenamento jurídico.

Em relação à mobilização de argumentos consequencialistas, estes foram utilizados em 58 casos, porém em apenas 13 o argumento foi predominante para a tomada de decisão vencedora, sendo reproduzido na ementa - ilustração nas figuras 9 e 10.

Figura 9 - Uso dos argumentos consequencialistas

Fonte: Autor

Figura 10 - Preponderância do argumento consequencialista para solução do caso ARGUMENTO CONSEQUENCIALISTA FOI
PREPONDERANTE PARA A SOLUÇÃO DO CASO?

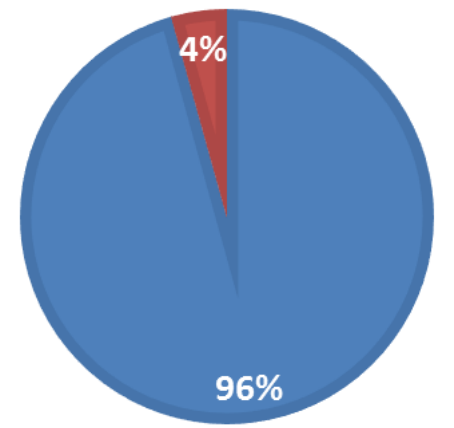

Não $\square$ Sim

Fonte: Autor

Os dados reforçam a hipótese de que Ministros consideram com muitas ressalvas as consequências econômicas nos seus votos, estabelecendo maiores exigências para mobilizar e avaliar esses argumentos como razões para decidir (ratio decidendi).

Além disso, as informações da figura 10 também permitem formular e confirmar uma descrição do STF como corte formalista - no que tange à escolha dos argumentos para fundamentar e tomar sua decisão - diante de casos de direitos econômicos e sociais com repercussão econômica 
em sede de controle concentrado.

Nesse sentido a transformação operada pela efetivação de direitos econômicos pode ocorrer por outras operações, para além da atuação dos tribunais - o que justifica, por exemplo, compreender o desenvolvimento nas últimas décadas de outras estruturas decisórias mais adequadas para o exame das consequências econômicas como o caso das câmaras de arbitragem.

Depreende-se, ainda, que mesmo em temas que, em tese, envolvam princípios e normas programáticas - exigindo a consideração das consequências sociais para a tomada de decisão -, a corte tende, quase que exclusivamente, a decidir com base em argumentos devidamente filtrados pelo direito, i.e., que sigam o conteúdo do programa condicionado, fixado por um sentido específico, e recebido em sua totalidade como uma razão decisória vinculante. Ao invés de se indagarem sobre "como seria se", nestes casos os Ministros operam, na maioria das vezes, com modelos "se X, então Y".

Uma possível justificativa subjacente a essa descrição decorre do fato de que o impacto das decisões em sede de controle concentrado é maior do que em outras ações e recursos, muitas vezes adstritas somente às partes litigantes - o que justificaria a cautela adicional dos Ministros em considerar outras consequências não jurídicas como razões de decisão, sobretudo porque afetam outras autoridades.

Os 58 casos nos quais se observou a mobilização de argumentos consequencialistas, exemplificam esse processo decisório em que razões condicionadas dos programas prevalecem em relação a argumentos consequencialistas. Ao diferenciar uma posição judicial original de outra consequencial, constata-se que Ministros tangenciam uma avaliação mais ampla e dados técnicos que escampam ao conhecimento da Corte - neste sentido é possível supor um certo uso velado do consequencialismo no país (SCHUARTZ, 2011).

Isto ocorre mesmo quando o STF acredita que a posição consequencial levaria a um resultado melhor, ou socialmente mais desejado, que o da posição formalista, porém os Ministros teriam que considerar outros fatores no conjunto e que por vezes lhe escapam por falta de estrutura ou formação. Este comportamento reforça o isolamento sistêmico da Corte, e não há garantias de que as expectativas da sociedade estejam sendo atendidas plenamente nos casos das ordens econômica e social. Existe, aqui, uma preocupação maior com as operações internas do sistema jurídico e um fortalecimento da atuação subótima da corte, que segue um tipo judicial original.

Nos casos de controle concentrado de constitucionalidade de direitos econômicos e sociais - que, pela matéria, já poderiam sugerir uma atuação catalisadora - dos últimos 30 anos, a incorporação de razões condicionadas e a jurisprudência limitaram os Ministros, os quais deixaram de considerar fatores que não estejam presentes ou que não tenham sido filtrados pelo sistema jurídico, ${ }^{14}$ justificando, talvez, o elevado número sentenças improcedentes ou que negam

14Este ponto é também ilustrado pelo recorrente debate em juízo acerca da discussão entre a reserva do economicamente possível vis-à-vis a proteção do mínimo vital, fundamentado no princípio da dignidade da pessoa humana. Para algumas análises, a teoria do mínimo vital serve como parâmetro objetivo para a tomada de decisão que afasta toda e qualquer discussão acerca da investigação da disponibilidade financeira da Administração Pública, que assume o ônus de comprovar o não tolhimento do mínimo vital à luz do caso concreto, por exemplo, veja o seguinte entendimento: "[...] Cabe ter presente, bem por isso, consideradas as dificuldades que podem derivar da escassez 
seguimento.

Estes 58 casos indicam, ademais, que um tribunal judicial original - situado no centro do sistema jurídico - não é sinônimo de corte formalista nem de dedutibilidade mecânica, ${ }^{15}$ sobretudo porque as consequências foram consideradas em 19\% dos casos, tendo sido, contudo rejeitadas na sequência como razões para decidir.

Por outro lado, essa subotimização e inflexibilidade diante das consequências podem prejudicar a estabilização do próprio sistema jurídico a longo prazo e propiciar o surgimento de outros centros de tomada de decisão concorrentes - como ocorreu com a expansão de tribunais arbitrais e de tribunais administrativos, além da "fuga do direito" dos tribunais judiciais para outras estruturas decisórias. ${ }^{16}$

Os achados apresentados devem ser cotejados considerando-se todas as limitações da amostra, uma vez que casos de controle concreto e difuso não foram incluídos - além, é claro, da atuação de outros órgãos e instâncias -, bem como o contexto social da história brasileira que justificou essas transformações.

Todavia, a amostra aponta para um recente aumento do uso deste argumento no STF, sobretudo a partir de 2010, sugerindo uma tímida abertura da Corte para este tipo de argumento como razão para decidir em sede de controle concentrado nos últimos anos.

Figura 11 - Uso dos argumentos consequencialistas a cada ano Fonte: Autor

Por fim, sopesando-se que a amostra incluiu apenas casos de direitos econômicos e sociais, era esperado um resultado que indicasse maior ocorrência de consequências econômicas e sociais em detrimento das consequências políticas, o que se verifica na figura 12:

Figura 12 - Tipo de argumento consequencialista na amostra

Fonte: Autor

\section{LEGITIMIDADE DOS JUÍZES NA ADJUCACÃO DOS DIREITOS ECONÔMICOS}

de recursos - com a resultante necessidade de o Poder Público ter de realizar as denominadas "escolhas trágicas" (em virtude das quais alguns direitos, interesses e valores serão priorizados "com sacrifício" de outros) -, o fato de que, embora invocável como parâmetro a ser observado pela decisão judicial, a cláusula da reserva do possível encontrará, sempre, insuperável limitação na exigência constitucional de preservação do mínimo existencial, que representa, no contexto de nosso ordenamento positivo, emanação direta do postulado da essencial dignidade da pessoa humana, tal como tem sido reconhecido pela jurisprudência constitucional desta Suprema Corte" (voto do Min. Celso de Mello no RE 580252, BRASIL, 2017).

15 Os problemas residiriam na ideia de que tribunais judiciais originais estão obrigados a aceitar e a seguir cegamente as regras, ou de que o formalismo se caracteriza como uma forma apolítica, mecânica e não responsiva de tomada de decisão. Na verdade, a observação indica o contrário: que mesmo uma corte prioritariamente formalista pode considerar argumentos extrajurídicos ao decidir. Trata-se, antes, de uma análise do tipo de comunicação produzida nos tribunais, do que propriamente do comportamento dos juízes. Se assim não o fosse, seria possível aproximar o comportamento de obediência cega às regras da visão do "juiz-computador", definição de Bańkowski e Schafer (2007).

16 Em vista disso, paradoxalmente, o protagonismo do STF também favoreceu o desenvolvimento de organizações extrajudiciais e concorrentes para a tomada de decisão. Cf., neste sentido, Barros (2018). 
Como interpretar a atuação do STF em relação à tomada de decisão no campo do direito econômico? Como visto na amostra selecionada a Corte optou na maioria dos casos em afastar o enfrentamento das consequências envolvidas. Por qual motivo os ministros adotaram este comportamento decisório? Seria possível admitir um problema em relação à legitimidade dos juízes na sociedade ao avançar no controle judicial de políticas públicas - esfera de competência atribuída tradicionalmente para a Administração Pública?

Do ponto de vista sistêmico, não faz sentido discutir legitimidade de juízes em aplicar direitos sociais e econômicos diante da constitucionalização destes direitos, que representou uma transformação de diferentes programas de políticas públicas em obrigações constitucionais. Não há nem mesmo que se debater a existência - ou não - de eleição de juízes para seus cargos, pois direitos econômicos e sociais são programas jurídicos, autorizando prima facie a intervenção judicial em face da arbitrariedade.

A efetivação destes direitos compreende uma nítida passagem do sistema político para o jurídico e, evidentemente, que sua centralidade não reside apenas no Executivo, por meio de suas agências públicas, mas também nos juízes, figuras nucleares para a aplicação desses direitos.

Em uma sociedade funcionalmente diferenciada e fragmentada, problemas sociais não são resolvidos somente pelo primado do sistema político; tribunais possuem significativa importância na imposição desses direitos e, em alguma medida, juízes assumem uma posição de poder dentro do sistema político, sobretudo diante do enfraquecimento do Estado nacional e da "libertação" do direito na sociedade mundial. ${ }^{17}$

Vale também destacar a posição e a importância desses direitos na sociedade. Dentro do sistema político, a constitucionalização desses direitos conferiu-lhes status prioritário diante de propostas não constitucionalizadas. A principal evidência disso talvez seja o princípio da não regressão - controlado no plano internacional pelo Comitê sobre Direitos Econômicos, Sociais e Culturais -, que impede, no plano doméstico, a redução de benefícios sociais existentes e estipula, ao menos em tese, que restrições se sujeitem a um exame mais rigoroso, a fim de determinar sua adequação.

O argumento da não regressão baseia-se no fato de que a implementação de direitos sociais e econômicos é progressiva, dada a escassez de recursos e o pouco acesso a saberes científicos

17 Considerando as transformações mencionadas na sociedade, Bruce Ackerman (2000, p. 73) fala numa nova separação dos poderes: "The separation of powers is a good idea, but there is no reason to suppose that the classical writers have exhausted its goodness. To the contrary. As we explored each of separationism's three rationales, we found plenty of reasons to question received American wisdom." Numa outra abordagem Fischer-Lescano e Möller (2016) observam o surgimento de novas arenas transnacionais de solução de conflitos em relação aos direitos econômicos e sociais, ultrapassando as soluções centralizadas nos Estados, afirmam que: "There are three diferent arenas where transnational social rights must be strengthened: A) at global level, the main challenge is to find a timely solutin to the threats to social rights posed, not by states, but by transtional corporations. At European level B), we have to make sure that a social Europe becomes a reality. This is of utmost importance with regard to the strengthening of transnational social rights: a social union which resist the temptation to establish imperial and exploitative (transnational) relations, could be a powerful resource which promotes social rights. Lastly, we must ensure that C) states and thepolitical organisations of global governance are held to the standard of the emanciparoty ideal" (FISCHER-LESCANO; MÖLLER, 2016, p. 36). Não restam dúvidas que tanto a nova separação dos poderes quanto o surgimento de novas arenas transnacionais de solução de conflitos a pontam para uma mudança na implementação dos direitos fundamentais, que exigem novas formas reflexivas de operar para além do Estado. 
enfrentado por muitos países. Estados devem abster-se de cortar subsídios de bens essenciais, como alimentos, água e energia, a fim de evitar causar sofrimento indevido às pessoas. Reduzir gastos com educação, cuidados de saúde ou outros serviços sociais constitui flagrante violação aos direitos econômicos, sociais e culturais, a menos que o Estado prove que não dispõe dos recursos necessários. Note-se que, como regra geral, a não regressão afirma que em qualquer nível de disponibilidade de recursos deve-se priorizar estes direitos, de modo que haja progresso contínuo em seu gozo pelos povos.

Tal perspectiva ganha relevância quando se compreende que direitos sociais e econômicos possuem um potencial democratizante, na medida em que colocam a ordem socioeconômica à disposição da sociedade. Fischer-Lescano e Möller (2017), inclusive, avançam no tema, sustentando que esses direitos são uma condição necessária para a radicalização do princípio da democracia, pois voltam-se contra todas as relações de dominação que se oponham à autonomia $\mathrm{e}$ à autodeterminação da sociedade (FISCHER-LESCANO; MÖLLER, 2017, p. 77-84).

Violações a estes direitos representam rupturas significativas no sistema político. É dizer, veda-se à Administração Pública a edição de normas ou regulamentos que prejudiquem o acesso aos direitos sociais e econômicos, sendo que esta deve assumir uma postura protetiva e assecuratória desses direitos - muitas vezes vinculados a um padrão mínimo de fruição (minimum core) -, respaldando-se em acordos e tratados internacionais.

Desta forma, sobreleva-se a questão do acesso à justiça. A tese dos sobreintegrados de Neves (2006) ganha relevância neste ponto. Não surpreende que os litigantes encontrados na amostra selecionada pertençam, em sua maioria, a órgãos do governo ou representam as demandas referentes às classes média e alta, que podem arcar com os altos custos judiciais. ${ }^{18}$ Como resultado, o Judiciário tende a ser uma arena exclusiva para soluções internas de interesses partidários - com a menção ao STF como "órgão de deliberação corporativa do Estado"19 - ou para requerentes privilegiados economicamente, deixando pouco espaço para uma transformação no que tange à adjudicação de direitos sociais e econômicos ou à justiça social. ${ }^{20}$

Além disso, ainda que tribunais determinem a governos que direcionem recursos para educação e cuidados de saúde, nada garante que essas decisões sejam efetivamente aplicadas. Direitos sociais e econômicos acabam, portanto, em alguns casos, sendo confirmado mais como expectativas normativas frustradas do que protegidas. Interessante é perceber que muitas vezes

18 Nesse sentido, sustenta Oliveira (2017, p. 145): "Ainda temos justiça demais para poucos e justiça de menos para a grande maioria da população brasileira. Basta olhar a pauta temática do Supremo para ver os interesses que a dominam, destacando-se o grande tempo que o tribunal dispende decidindo sobre aumento ou contenção de privilégios de carreiras públicas do Estado, e sobre o destino de atores políticos que contam com foro privilegiado". Sobre a discussão dos perfis dos litigantes e dos custos envolvidos na adjudicação do direito à saúde no Brasil, Cf. Ferraz (2014) e Wang (2015).

19 Cf. Oliveira (2016).

20 Isto ficou evidenciado no julgamento conjunto - ainda em andamento - dos recursos extraordinários 566471 e 657718, que discutem o fornecimento de remédios de alto custo não disponíveis na lista do Sistema Único de Saúde e de medicamentos não registrados na Agência Nacional de Vigilância Sanitária. O Ministro Luís Roberto Barroso defendeu como regra geral o não fornecimento de medicamentos não listados pelo Sistema Único de Saúde. A liberação por decisão judicial só seria admitida numa situação excepcional e propôs uma série de requisitos a serem observados pelo juiz para obrigar o governo a fornecer o remédio, dentre o qual se destacava a incapacidade financeira do paciente, diz o Ministro: "A vida e a saúde de quem tem condições de ir a juízo não tem mais valor do que as dos muitos que são invisíveis para o sistema de Justiça”. 
a questão da reserva do possível levantada pela Administração Pública, para a adjudicação da Corte também não está necessariamente ligada ao limite econômico do Estado, mas sim ao limite econômico em relação à concretização de direitos fundamentais. Todavia, por carecer de subsídios para definir essa dimensão econômica dos direitos fundamentais, a Corte prefere afastar a discussão e se limitar a proferir uma decisão que discuta a razoabilidade da pretensão vis-à-vis o enfrentamento do tema da disponibilidade de recursos. ${ }^{21}$

Não se nega, contudo, a contrapartida da adjudicação desses direitos, como um controle judicial dos atos da Administração Pública: passa-se a exigir que decisões políticas futuras sejam direcionadas àqueles mais necessitados e subintegrados nos sistemas sociais, sobretudo se a maioria dos beneficiários destas decisões já está sobreintegrada. ${ }^{22}$

Diante destas considerações, é relevante entender a complexidade que envolve a adjudicação desses direitos. Tradicionalmente, tribunais têm sido refratários a procedimentos que visam à implementação de direitos econômicos, ou a mecanismos alternativos que lidam com problemas distributivos. Talvez isto ocorra no Brasil, pois as principais operações no Judiciário decorrem de demandas individuais (e não coletivas), exigindo, portanto, soluções mais criativas para problemas redistributivos. Neste sentido, o problema encaminha-se para uma discussão sobre a capacidade institucional.

\section{CAPACIDADE INSTITUCIONAL DOS JUÍZES NA ADJUDICAÇÃO DOS DIREITOS ECONÔMICOS}

Debater sobre capacidade institucional significa discutir como direitos econômicos são adjudicados a partir do enfoque das estruturas disponíveis para a tomada de decisão pela autoridade. De modo geral, é possível fazer duas distinções: decisões de deferência e decisões de não deferência. No primeiro caso, tribunais abstêm-se de decidir alegando que se trata de uma atribuição do sistema político que depende exclusivamente da atuação do Poder Executivo por meio de seus programas que possibilitam um melhor planejamento (eg., contratos administrativos, concessões e outorgas, termos de parcerias e cooperação entre outros modelos negociais). Nesta posição, sustenta-se que alguns países sequer preveem constitucionalmente estes direitos, o que, portanto, inviabilizaria sua adjudicação.

Todavia, este argumento não subsiste, pois mesmo nestes países que não dispõem

21 A comprovação da aplicabilidade da reserva do possível se torna um ônus da Administração Pública, havendo a necessidade de que se evidenciar a indisponibilidade de recursos e o justo motivo em não atender determinada pretensão individual ou coletiva. Veja, por exemplo, o voto do min. Barroso: "No caso em questão, já seria suficiente para afastar a incidência da cláusula da reserva do possível o fato de que o Estado não se desincumbiu do ônus da prova da insuficiência de recursos para custear a indenização assegurada ao preso. Na verdade, o recorrido limitouse a argumentar, de forma genérica, que não há disponibilidade orçamentária para garantir melhor tratamento aos presos. O Estado não trouxe nenhum elemento capaz de demonstrar que não teria capacidade financeira para o pagamento da indenização pecuniária ao recorrente " fixada no valor de R $\S 2$ mil" ou para conceder o mesmo direito aos presos que se encontrem na mesma situação. Não se pode, porém, admitir a invocação da cláusula da reserva do possível como argumento meramente retórico, de modo a permitir que o poder público se exima de seus deveres legais, inclusive de reparação dos danos por ele causados" (BRASIL, 2017).

22 A distinção entre subintegrados e sobreintegrados está em Neves (2006), que discute a aplicação da teoria dos sistemas no caso brasileiro. 
expressamente sobre direitos econômicos e sociais no texto constitucional - como no caso dos Estudos Unidos da América - há sua concretização pelos tribunais. Neste sentido, ilustrativamente, observa-se a atuação da Suprema Corte dos Estados Unidos no caso Dandridge v. Williams, que discutiu se uma lei do Estado de Maryland que fixou um padrão para determinar a necessidade de benefício para famílias com crianças dependentes violava a cláusula de proteção à igualdade (equal protection clause).

Mesmo sem uma previsão na constituição estadunidense sobre benefícios ou programas de assistência social, o tribunal concluiu que não houve violação à cláusula de proteção à igualdade. A decisão baseou-se em precedentes para indicar que o programa era "um esquema de federalismo cooperativo" e deu ao Estado "poder indiscutível" para calcular o padrão de necessidade. O tribunal argumentou, ainda, que "o estatuto federal não proíbe um Estado de equilibrar os estresses que a ausência de pagamentos impõe as famílias hipossuficientes diante da maior capacidade financeira das famílias numerosas para acomodar suas necessidades” (US SUPREME COURT, 1970).

No caso de decisões de não deferência, admite-se a adjudicação pelos tribunais. No entanto, o grau de interferência judicial varia, oscilando entre orientações moderadas, recomendações ou mesmo determinações concretas e ordens de implementação, criando novas obrigações e direitos. Ilustrando uma ação intervencionista moderada, retome-se o famoso caso Governo da República da África do Sul v. Grootboom e outros, decisão da Corte Constitucional da África do Sul que, diante do despejo de inúmeras famílias alojadas em propriedade privada de terceiro, reconheceu a obrigação do Estado de fornecer-lhes abrigo adequado, independentemente da disponibilidade de recursos. Especificamente, a corte não impôs condições de execução da obrigação, apenas exigiu que o Estado adotasse medidas razoáveis para cumprir o dever de fornecer abrigo a famílias desamparadas. ${ }^{23}$

Há, evidentemente, soluções mais intervencionistas, como a da Corte Constitucional da Colômbia, que inaugurou a tese de "estado de coisas inconstitucional". Este argumento depende, primordialmente, da avaliação dos seguintes critérios: (i) violação maciça e generalizada de vários direitos constitucionais que afete um número significativo de pessoas; (ii) descumprimentos sucessivos por parte das autoridades de suas obrigações de garantia dos direitos; (iii) uso reiterado de práticas inconstitucionais, demandando uma ação de tutela (acción de tutela) para garantir o(s) direito(s) violado(s); (iv) a ausência de medidas legislativas, administrativas ou orçamentárias que evitem a violação de direitos; (v) a existência de um problema social cuja solução exija a intervenção de várias entidades - e.g., mobilização de um conjunto complexo e coordenado de ações e uma quantidade de recursos que requer um esforço orçamentário adicional importante; (vi) inviabilidade de proteção individual.

No caso concreto, a corte colombiana reconheceu este estado de coisas inconstitucional

\footnotetext{
23 Destaca-se seguinte passagem do voto: "Estou consciente de que é uma tarefa extremamente difícil para o Estado cumprir essas obrigações dadas as condições que prevalecem em nosso país. Isto é reconhecido pela Constituição, que prevê expressamente que o Estado não é obrigado a ir além dos recursos disponíveis ou a realizar esses direitos imediatamente. Afirmo, no entanto, que, apesar de todas essas qualificações, estes são direitos, e a Constituição obriga o Estado a dar-lhes efeito. Esta é uma obrigação que os tribunais podem em circunstâncias apropriadas imporem" (SOUTH AFRICA, 2000, p. 65, tradução nossa).
} 
devido à omissão das autoridades de prover cuidados a milhares de pessoas sem moradia que sofriam múltiplas violações a seus direitos humanos. Em contraste à demanda sul-africana, reconheceu-se que as violações aos direitos eram falhas estruturais profundas do Estado colombiano, posicionamento que resultou numa série de ordens concretas com o intuito de remediar as insuficiências orçamentária e administrativa, além de tentar estabelecer níveis mínimos de proteção dos direitos dessas pessoas em tempo razoável.

No Brasil, mesmo sem previsão expressa na Constituição ou em qualquer texto legal, o STF reconheceu, no julgamento parcial da ADPF 347, a tese que "confere ao Tribunal uma ampla latitude de poderes", entendendo "que a técnica só deve ser manejada em hipóteses excepcionais, em que, além da séria e generalizada afronta aos direitos humanos, haja também a constatação de que a intervenção da Corte é essencial para a solução do gravíssimo quadro enfrentado" (BRASIL, 2015).

Nesta ADPF, debate-se a situação atual do sistema penitenciário brasileiro, que viola preceitos fundamentais da $\mathrm{CF} / 88 \mathrm{e}$, em especial, direitos fundamentais dos presos. Ainda sem solução definitiva, o plenário já se manifestou preliminarmente no sentido de reconhecer o cabimento da ação diante do quadro de violação massiva e persistente de direitos fundamentais decorrente de falhas estruturais e da falência de políticas públicas e cuja modificação depende de medidas abrangentes de natureza normativa, administrativa e orçamentária. Neste sentido, o STF determinou a liberação das verbas do Fundo Penitenciário Nacional e tornou mandatória a realização de audiências de custódia por tribunais e juízes inferiores.

Subjaz a estas análises a compreensão de como o tribunal pode adjudicar esses direitos. Como apontado por De Giorgi, Faria e Campilongo (2015): “[m]as até que ponto a Justiça pode atender às expectativas de quem vê seus direitos negados por falta de políticas públicas?”. Ainda prosseguem os autores, afirmando que "[n]o plano dos ideais, estamos diante de valores políticos fundamentais para a coesão social, é certo. Mas o Direito opera no plano das realidades sociais e econômicas que é capaz de construir e controlar. Assim, invocar o ECI pode causar mais dificuldades à eficácia da Constituição do que se imagina".

Retomando-se o caso colombiano, a situação das pessoas vulneráveis tem se agravado a despeito dos esforços daquela corte. Deve-se lembrar, inclusive, que tribunais podem desdobrar os riscos que não podem assumir em seu ambiente, possivelmente acarretando maiores perigos para outros sistemas sociais. As estruturas que operam para reduzir os riscos tornam-se um perigo para as partes afetadas em seu ambiente.

É ilusão acreditar que a afirmação de que o "estado de coisas inconstitucional" é capaz de resolver todos os problemas sociais pela judicialização. Novamente, concorda-se com De Giorgi, Faria e Campilongo (2015) que afirmam que "[n]um país marcado pelos sem-teto, sem-saúde, semeducação e sem-segurança, o conceito de ECI despreza o fato de que o sistema jurídico não tem estruturas, meios e organizações que lhe permitam corrigir essas mazelas por sentenças judiciais".

Ninguém nega as dificuldades estruturais enfrentadas pelos tribunais ao apreciar estas demandas, especialmente proferir uma sentença que consiga avaliar consequências extrajudiciais. 
Em termos sistêmicos, é preciso reconhecer os déficits de filtragem e de formalização envolvidos na passagem entre periferia e centro - que representam óbices à atuação dos tribunais ${ }^{24}$-, bem como afirmar as mudanças na semântica da teoria do direito sobre como lidar com estes casos a fim de não incorrer em arbitrariedades.

No início deste texto discutiu-se a importância de definir a metodologia capaz de vincular direito e econômica. A importância desta definição decorre da própria obrigatoriedade da operação de um direito racional e formal - na orientação weberiana - capaz de estabelecer com clareza para os jurisdicionados os critérios para a seleção e avaliação das consequências. Caso contrário, a estrutura decisória do Judiciário poderia comprometer a observação de regras preestabelecidas pelo ordenamento, acarretando em indistinção em relação às operações jurídicas.

Entretanto, deve-se considerar, também, que estas ações excepcionais impõem e demandam outra postura do sistema político, ou, nos dizeres de Rodriguez (2015), pretendem “constranger e manter alertas os donos do poder para evitar o arbítrio. A separação dos poderes nunca foi pensada como regra administrativa a impor uma divisão estanque de funções entre dois, três, quatro, ou entre quantos forem os poderes do Estado".

Trata-se de reconhecer a atuação de uma corte catalisadora e a pergunta é saber se estratégias e interesses fora do direito estão sendo ocultados? Talvez, mas, como já mencionado, direitos econômicos representam uma forma de controle do governo e, portanto, são modelos que implicam em renovação das operações jurídicas e são uma condição necessária para a radicalização do princípio democrático. ${ }^{25}$ É forçoso reconhecer o caráter político desses direitos e, portanto, a existência de múltiplas arenas de discussão dessas demandas e a competência dos tribunais para adjudicá-los. Caso contrário - sem as reivindicações - não seria possível realizar expectativas normativas já asseguradas pelo direito, que são rotineiramente frustradas, ou produzir novas expectativas.

Não é o caso, porém, de admitir falsas críticas de que estes direitos são demasiadamente vagos e dependentes de recursos, ${ }^{26}$ revelando-se, destarte, inexigíveis. Vale lembrar que todo e qualquer direito é determinado por meio de uma decisão e que muitos direitos individuais dependem de recursos - e.g., a implementação de um sistema de proteção de patentes -, ao passo que diversos conflitos de direitos sociais e econômicos não demandam investimentos vultosos evitar a poluição do rio, reconhecer direitos indígenas, não ordenar o despejo de famílias, entre outras, são ações de baixo custo.

Da mesma forma, é possível observar a atuação dos tribunais às margens de outros sistemas sociais, pois, no fundo, eles se revelam, enquanto organizações sociais, uma arena de disputas políticas, participando do jogo entre governo/oposição. Novamente, na amostra selecionado percebeu-se o importante papel desempenhado pelos partidos políticos como litigantes em face da implementação de políticas econômicas. Pontue-se, contudo, que isto não ocorre apenas nos

24 Cf. Villas Bôas Filho (2009) e Campilongo (2002).

25 Cf. Fischer-Lescano e Möller (2017, p. 59-84).

26 O argumento da dependência de recursos foi popularizado no Brasil a partir da doutrina produzida pelo Ministro Gilmar Mendes ao glosar decisões da Corte Constitucional alemã que recorriam à teoria da reserva do possível. Para uma crítica da incorporação desta teoria no Brasil, cf. Correia (2014, p. 132-142). 
casos de adjudicação de direitos sociais e econômicos, mas também naqueles que não implicam necessariamente garantias da sociedade, que servem de barganha para outros interesses da organização.

Sublinhe-se, por ser relevante, que casos de direitos econômicos exigem uma reflexão sobre como a observação dos tribunais na sociedade ocorre, bem como uma consideração a respeito de outras estruturas de tribunais e novos desenhos institucionais. ${ }^{27}$

O STF, segundo os apontamentos já feitos, na prática, a proteger esses direitos propondo soluções "menos" intervencionistas ou por meios "negativos" - e.g., declarar a inconstitucionalidade de uma lei ou ato administrativo -, ou, ainda, buscando uma resposta individual. Estes são desfechos "tradicionais" aos quais tribunais judiciais originais recorrem com frequência, sobretudo ao se deparar com problemas retributivos que dependem quase exclusivamente da provisão estatal.

No entanto, é possível observar novos arranjos de controle e adjudicação judicial, tais como as formas fracas de controle de constitucionalidade, ${ }^{28}$ que exigem uma visão mais colaborativa e dialógica entre os poderes do Estado e oferecem potencialmente benefícios para reduzir as pressões depositadas por decisões judiciais sobre organizações políticas, pois admitem a necessidade de interação e deliberação legislativa.

Não há dúvidas também de que tribunais arbitrais ou administrativos resolvem mais facilmente problemas referentes à determinação de gastos relacionados a serviços e bens sociais, que geralmente devem ser apreciados por grande parte da sociedade e dependem da incorporação de profissionais com outra formação para decidir. Todavia, vale ressaltar que nem sempre organizações paraestatais e privadas podem contribuir enormemente propondo soluções inovadoras para as deficiências estatais diante de sua incompetência econômica. ${ }^{29}$

Em alguns casos de adjudicação, os conflitos distributivos ultrapassam o raciocínio retributivo (jogos de soma zero) ou soluções ganha-perde das ações judiciais tradicionais (escolher quem está certo ou errado na lide). Neste sentido, a arbitragem de direitos econômicos consegue produzir decisões negociadas sobre a utilização de recursos materiais ou equacionar, a partir dos interesses das partes, questões orçamentárias e regulatórias. Estas decisões exigem mediação, negociação, construção de critérios para avaliação e incentivos para soluções de construção

27 Reitera-se a opinião de Amato (2017, p. 294) de que não há muitas opções de abertura à competição privada nem adequada regulação que favoreça parcerias e cooperações para a implementação de programas sociais. O modelo das políticas públicas precisa superar técnicas rudimentares e centralizadas de prestação dos serviços para "incorporar em seu desenho institucional, de um lado, formas de descentralização capazes de manter mecanismos de redistribuição, de propagação das experiências de sucesso e de mensuração de desempenho e, de outro lado, procedimentos para a audiência das partes interessadas".

28 Segundo a caracterização de Gardbaum (2013), o modelo fraco, desenvolvido e praticado em países da commonwealth, possui três características essenciais: (1) a existência de uma declaração de direitos; (2) a conferência de alguma forma de poder superior judicial para fazer valer esses direitos através da avaliação da consistência da legislação e de outros atos governamentais com esses direitos fundamentais, que devem ir além da presunção tradicional e dos modos comuns de interpretação normativa; e, mais claramente, (3) a existência de uma legislatura que tenha a palavra final sobre a constitucionalidade das leis no país, por maioria simples. Para uma discussão da aplicação do controle de constitucionalidade fraco no Brasil, cf. Barros (2017) e em outros países após processos de democratização, cf. Gardbaum (2015).

29 Assim, destaca-se a importância da família na educação, do empreendedorismo e da universidade no desenvolvimento de políticas industriais e comerciais, das parcerias público-privadas na gestão de áreas da saúde e habitação. Estas organizações, diferentemente do Estado, decidem a partir de um raciocínio distributivo e proporcional capaz de mediar o acesso simultâneo de indivíduos e grupos distintos a estes serviços para além da disponibilização estatal. 
conjunta - e não como resultado de uma subsunção a regras ou a construções adversativas -, cabendo somente aos tribunais judiciais sua homologação e sua execução.

Do ponto de vista sistêmico, não se pode considerar a adjudicação de direitos econômicos apenas como uma técnica de compensação, porque a autoridade é compelida a compreender os riscos e os perigos da decisão quando estes direitos estão em juízo. Uma vez que decisões podem produzir exclusão diante de potenciais beneficiários, não é possível pensar em organizações insensíveis às consequências da decisão, ainda que não consigam antecipar seus perigos ambientais.

Em suma, não há um tribunal mais adequado, ou mais desejável. Aponta-se, aqui, que a adjudicação de direitos econômicos e sociais com repercussões econômicas funciona com paradoxos que devem ser observados e desdobrados pela autoridade decisória a partir de estruturas sensíveis ao ambiente. Muitas vezes, é possível controlar os riscos e minimizar as exclusões da decisão quando estas são limitadas temporalmente - i.e., assegurando-se de que as exclusões não se tornem permanentes, ou de que os paradoxos não se desdobrem e acarretem problemas mais severos para a sociedade. Nestas situações de decisão, há riscos de arbitrariedade - i.e., aqueles que não se relacionam com a própria atividade decisória, não atendem aos interesses negociados ou a descumprimentos no momento da execução.

\section{CONSIDERAÇÕES FINAIS}

Este texto discutiu como a temática do ativismo judicial ou da judicialização da política pode ser encaminhada por outro enfoque sociológico a partir das análises da argumentação judicial em demandas envolvendo direitos econômicos. A ênfase, aqui, recaiu nas considerações das consequências no processo de tomada de decisões pelos juízes.

O texto adotou um recorte para mostrar que, na prática, em muitos casos, são os próprios Ministros que definem quando e como vão considerar os efeitos das consequências extrajurídicas durante o julgamento. A falta de padrão argumentativo é a regra geral extraída destas análises. ${ }^{30}$ Para além desta constatação também foi importante observar os tipos de interesses que são arbitrados no STF enquanto corte constitucional, sobretudo na defesa dos direitos econômicos e sociais, que, geralmente, são monopolizados pela Associação/Confederação/Sindicato, seguido por Governador e Partido Político.

É certo que estes dados representam um pequeno percentual da totalidade de decisões que a corte profere todo ano, inclusive no controle abstrato. Todavia, a pesquisa revela problemas e questões que são comuns na adjudicação em geral de casos que exigem a seleção e avaliação das consequências para a tomada de decisão. ${ }^{31}$

30 No estudo apresentado constatou-se que o STF, por razões institucionais, pode hoje ser ao mesmo tempo uma corte original e peremptória, deferencial, consequencial e catalisadora já que pode escolher quem, quando e como julgar. Para além das inúmeras garantias funcionais e institucionais, prevalece um adicional reforço que permite a irrestrita independência dos Ministros já que o STF pode determinar as suas próprias competências, possibilitando decidir como operar, inclusive, em qualquer sistema social.

31 Neste sentido, não importa tanto o recorte processual, pois ações constitucionais, recursos extraordinários e outras ações oraodinárias podem lidar com os problemas das consequências para a tomada de decisão do mesmo modo. 
Este texto defende que a análise destes tipos de julgados é um bom medidor para verificar como os limites do direito vem sendo estabelecidos pelos tribunais vis-à-vis a inócua discussão do ativismo ou da judicialização. É o caso, portanto, de reconhecer a necessidade de ampliar um campo de estudo sociológico da argumentação jurídica e dos tribunais, enfatizando a adjudicação de direitos econômicos e sociais. Em breve síntese, é possível dizer que esse ramo da sociologia jurídica se preocupa em estudar a atuação dos tribunais da sociedade, abrangendo temas como modelos de trajetória do Estado e sua articulação com o Judiciário, formas de organização e comunicação organizacional, formas de recrutamentos e gestão dos tribunais, comunicação judicial, processos de economização ou politização dos tribunais. Desta forma, este campo de pesquisa pressupõe uma teoria social ao mesmo tempo que se vale de embasamento empírico.

Ponto sustentado foi que direitos econômicos são importante forma jurídica capaz de revelar as tensões da sociedade e, ao mesmo tempo, possibilitar um processo de experimentação e coordenação entre diferentes organizações, não apenas em relação ao Estado. Ainda, a dificuldade notada nas adjudicações do direito sobre a econômica pode indicar sinais de esgotamento do modelo intervencionista do Estado - inclusive das cortes - como suposto garantidor de todas as melhorias da sociedade, bem como revela formas alternativas de solução de conflitos e de formação de relações de cooperação e coordenação entre indivíduos e organizações sociais.

Direito e economia devem e podem, por sua vez, irritar e gerar ruídos nos respectivos subsistemas por meio de novos conhecimentos. No caso dos tribunais, estes devem zelar para a formação de padrões dentro de uma ordem estrutural das decisões - distribuindo o novo conhecimento no interior do sistema, sem comprometer a vedação do non liquet e a proteção das expectativas normativas. Qual é o limite? É o caso de observar a capacidade de auto-organização da própria sociedade, inclusive para bloqueio.

\section{REFERÊNCIAS}

ACKERMAN, Bruce. The new separation of powers. Harvard Law Review, Cambridge, v. 113, n. 3, p. 633-729, Jan. 2000.

AMATO, Lucas Fucci. Imaginação constitucional: direitos humanos, cultura e desenvolvimento em Luhmann e Unger. 2017. 419 f. Tese (Doutorado em Direito) - Faculdade de Direito, Universidade de São Paulo, São Paulo, 2017.

BAŃKOWSKI, Zenon; SCHAFER, Burkhard. Double-click justice: legalism in the computer age. Legisprudence, Oxford, v. 1, p. 31-49, 2007.

BARROS, Marco Antonio Loschiavo Leme de. Constitutional design and the Brazilian judicial review: remarks about strong and weak-form review in the Brazilian Federal Supreme Court. Revista Opinião Jurídica, Fortaleza, v. 15, n. 20, p. 180-206, jan./jun. 2017.

BARROS, Marco Antonio Loschiavo Leme de. Sociedade, direito e concorrência: reflexões sociológicas sobre o Sistema Brasileiro de Defesa da Concorrência. Curitiba: Juruá, 2018. 
BRASIL. Supremo Tribunal Federal. Arguição de Descumprimento de Preceito Fundamental 449 Distrito Federal. Relator: Min. Luiz Fux, 8 de maio de 2019. Disponível em: http://redir.stf. jus.br/paginadorpub/paginador.jsp?docTP=TP\&docID=750684777. Acesso em: 15 out. 2019.

BRASIL. Supremo Tribunal Federal. Medida Cautelar na Argüição de Descumprimento de Preceito Fundamental 347 Distrito Federal. Relator: Min. Marco Aurélio, 9 de setembro de 2015. Disponível em: http://redir.stf.jus.br/paginadorpub/paginador. jsp?doc TP=TP\&docID=10300665. Acesso em: 13 jan. 2017.

BRASIL. Supremo Tribunal Federal. Recurso Extraordinário 580.252 Mato Grosso do Sul. Relator: Min. Alexandre de Moraes, 16 de fevereiro de 2017. Disponível em: http://www.stf. jus.br/portal/processo/verProcessoPeca.asp?id=312692053\&tipoApp=.pdf. Acesso em: 20 dez. 2017.

CAMPILONGO, Celso. Política, sistema jurídico e decisão judicial. São Paulo: Max Limonad, 2002.

CARNELUTTI, Francesco. Como nasce o direito. Belo Horizonte: Líder Cultura Jurídica, 2001.

COMPARATO, Fábio Konder. O indispensável direito econômico. Revista dos Tribunais, São Paulo, v. 101, n. 923, p. 37-52, 2012.

CORREIA, José Gladston Viana. Sociologia dos direitos sociais: escassez, justiça e legitimidade. São Paulo: Saraiva, 2014.

DE GIORGI, Raffaele; FARIA, José Eduardo; CAMPILONGO, Celso. Estado de coisas inconstitucional. O Estado de S. Paulo, São Paulo, 19 set. 2015. Disponível em: http://opiniao. estadao.com.br/noticias/geral,estado-de-coisas-inconstitucional,10000000043. Acesso em: 30 out. 2015.

FALCÃO, Joaquim; ARGUELHES, Diego Werneck; RECONDO, Felipe (org.). Onze supremos: o Supremo em 2016. Belo Horizonte: Letramento, 2017.

FALCÃO, Joaquim; CERDEIRA, Pablo de Camargo; ARGUELHES, Diego Werneck. I relatório supremo em números: o múltiplo Supremo. Rio de Janeiro: FGV, 2011.

FARIA, José Eduardo. O Supremo e o ativismo judicial. O Estado de São Paulo, São Paulo, 11 mar. 2017. Disponível em: http://opiniao.estadao.com.br/noticias/geral,o-supremo-e-o-ativismojudicial,70001695353. Acesso em: 25 maio 2017.

FERRAZ JUNIOR, Tércio Sampaio. Argumentação jurídica. São Paulo: Manole, 2014.

FERRAZ, Octavio. Between activism and deference: social rights adjudication in the Brazilian Supreme Federal Tribunal. In: GARCÍA, Helena; KLARE, Karl; WILLIAMS, Lucy (ed.). Social and economic rights in theory and practice: a critical assessment. New York: Routledge, 2014. p. 121-137.

FISCHER-LESCANO, Andreas; MÖLLER, Kolja. Transnationalisation of social rights. Cambridge: Intersentia, 2016. 
FISCHER-LESCANO, Andreas; MOLLER, Kolja. Luta pelos Direitos Sociais Globais. Rio de Janeiro: Lumen Juris, 2017

GARDBAUM, Stephen. Are strong constitutional courts always a good thing for new democracies? Columbia Journal of Transnational Law, New York, v. 53, n. 2, p. 285-320, 2015.

GARDBAUM, Stephen. The new commonwealth model of constitutionalism: theory and practice. Cambridge: Cambridge University Press, 2013.

GARGARELLA, Roberto; DOMINGO, Pilar; ROUX, Theunis (ed.). Courts and social transformation in new democracies: an institutional voice for the poor? London: Routledge, 2006.

LADEUR, Karl-Heinz. Crítica da ponderação na dogmática dos direitos fundamentais: apelo para uma renovação da teoria liberal dos direitos fundamentais. In: CAMPOS, Ricardo (org.). Crítica da ponderação, método constitucional entre a dogmática jurídica e a teoria social: ensaios traduzidos. São Paulo: Saraiva, 2016. p. 133-224.

LUHMANN, Niklas. Direito da sociedade. São Paulo: Martins Fontes, 2016.

NEVES, Marcelo. Entre Têmis e Leviatã: uma relação difícil. São Paulo: Martins Fontes, 2006.

NOBRE, Marcos; RODRIGUEZ, José Rodrigo. "Judicialização da política": déficits explicativos e bloqueios normativistas. Novos Estudos CEBRAP, São Paulo, n. 91, p. 5-20, 2011.

OLIVEIRA, Fabiana Luci de. Agenda suprema: interesses em disputa no controle de constitucionalidade das leis no Brasil. Tempo Social, São Paulo, v. 28, n. 1, p. 105-133, 2016.

OLIVEIRA, Fabiana Luci de. O Supremo Tribunal Federal e a política no Brasil contemporâneo. Cadernos Adenauer, Rio de Janeiro, v. 18, n. 1, p. 125-148, 2017.

RODRIGUEZ, José Rodrigo. Estado de coisas surreal. Jota. 25 set de 2015. Disponível em: $<$ https://jota.info/artigos/estado-de-coisas-surreal-25092015>. Acessado em 02 dez. de 2019.

SCHUARTZ, Luiz Fernando. Consequencialismo jurídico, racionalidade decisória e malandragem. In: MACEDO JÚNIOR, Ronaldo Porto (org.). Direito e interpretação: racionalidades e instituições. São Paulo: Saraiva, 2011. p. 383-418.

SOUTH AFRICA. Constitutional Court. Government of the Republic of South Africa and Others v Grootboom and Others. Johannesburg: Constitutional Court of South Africa, 2000. Disponível em: http://www.saflii.org/za/cases/ZACC/2000/19.pdf. Acesso em: 15 out. 2018.

TAYLOR, Matthew. Judging Policy: Courts and Policy Reform in Democratic Brazil. Stanford: Stanford University Press, 2008.

TUSHNET, Mark. Taking the constitution away from the courts. Princeton: Princeton University Press, 1999.

US SUPREME COURT. Dandridge v. Williams, 397 U.S. 471 (1970). In: JUSTIA. Mountain View, 1970. Disponível em: https://supreme.justia.com/cases/federal/us/397/471/. Acesso em: 18 
set. 2016.

VILLAS BÔAS FILHO, Orlando. Teoria dos sistemas e o Direito brasileiro. São Paulo: Saraiva, 2009.

WALDRON, Jeremy. Five to four: why do bare majorities rule on courts? Yale Law Journal, New Haven, n. 6, p. 1626-2133, Apr. 2014.

WANG, Daniel Wei Liang. Right to health litigation in Brazil: the problem and the institutional responses. Human Rights Law Review, Oxford, v. 15, n. 4, p. 617-641, Dec. 2015.

Como citar: BARROS, Marco Antonio Loschiavo Leme de. Direitos econômicos, sociedade e o supremo tribunal federal: observando a atuação da corte no controle abstrato. Scientia Iuris, Londrina, v. 24, n. 1, p. 99-123, mar. 2020. DOI 10.5433/21788189.2020v24n1p99. ISSN 21788189.

Recebido em: 11/12/2019

Aprovado em: 20/02/2020 